\title{
Skeletocutis jelicii: a new member of the Finnish polypore flora
}

\author{
HEIKKI KOTIRANTA
}

KOTIRANTA, H. 1984: Skeletocutis jelicii: a new member of the Finnish polypore flora. - Karstenia 24: 73-76.

A polypore species, Skeletocutis jelicii Tortić \& David, hitherto known only from Yugoslavia, is reported from Finland. It differs from all the other species of Skeletocutis Kotl. \& Pouz. found in Finland by its monomitic hyphal system and small subglobose spores. The three collections were made from very decayed coniferous wood in protected areas.

$S$. jelicii is thoroughly redescribed and illustrated. Its distribution and ecology, and also the concept of the genus Skeletocutis are briefly discussed.

Heikki Kotiranta, Department of Botany, University of Helsinki, Unioninkatu 44, SF00170 Helsinki, Finland

\section{Introduction}

I can hardly have been the only polyporologist who was confused by Keller's (1979) transfer of the known species of Incrustoporia Dománski (except I. carneola (Bres.) Ryv.) to Skeletocutis. However, the instructive scanning electron microgaphs showed that Incrustoporia species have the same kind of crystals on the hyphae as Skeletocutis amorpha (Fr.) Kotl. \& Pouz. The uniformity in the ultrastructure of these crystals in Incrustoporia and Skeletocutis is so great and exceptional, that it was naturally considered to indicate a very close relationship between these two genera. The narrow, allantoid spores and the dimitic hyphal system are also very similar. Skeletocutis had earlier been supposed to be a monotypic genus, unlike the widely distributed and well-known genus Incrustoporia. As Keller states, however, Skeletocutis (Kotlaba \& Pouzar 1958) is older than the more informative generic name Incrustoporia (Dománski 1963), and if the congenericity is accepted, the rules of nomenclature require that the Incrustoporia species should be transferred to Skeletocutis.

In later papers (Tortić \& David 1981, David 1982) monomitic species have also been described under or transferred to Skeletocutis (S. azorica David, S. jelicii Tortić \& David, S. portcrosensis David, S. subphaerospora David). Some of them have broadly ellipsoid or subglobose spores (S. azorica, S. jelicii, S. subphaerospora), which does not fit very well with the original concept ot the genus (Kotlaba \& Pouzar 1958). However, the differences are not so significant that those species need a genus of their own. In her monograph of Skeletocutis, David (1982) has demonstrated convincing, that the members of this group have several important features in common, which justify broadening the old concept of the genus Skeletocutis.

$S$. jelicii is one of the least known members of the genus, having been described on the basis of a single Yugoslavian collection. The oldest collection of $S$. jelicii was made in southern Central Finland by Niemelä as early as 1966. However, it remained undetermined until further Finnish specimens were found. During my visit to the University of Göteborg on January 1984, I showed a specimen to Dr. Nils Hallenberg, who strongly suspected that it was $S$. jelicii, described by Tortic and David (1981). The specimen was carefully studied later in Helsinki, and proved to accord with the descriptions of the type of S. jelicii. A third collection of this species was subsequently found.

\section{Skeletocutis jelicii Tortić \& David}

Fruit body annual, resupinate, $5-15 \mathrm{~cm}$ wide, closely adnate, confluent - effused, $0.3-0.6 \mathrm{~mm}$ thick, slightly ceraceous, pore layer smooth, with small guttation depressions $(0.5-1.5 \mathrm{~mm}$ in diam) in oldest parts. Margin distinct in old parts, in young, actively growing parts sterile and very narrow. Pores small, 7-9 (-10) per $\mathrm{mm}$, hardly visible to the naked eye, isodiametric to almost rounded, thin- to moderately thick-walled, cracking in oldest parts, finely velutinous under lens $(\times 50)$, because of projecting hyphal ends. Pore surface first white, but soon with brown flecks when fresh, turning pale cream to light ochrebrown with dirty brown spots when dry. Smell, when fresh pungent, 'bedbug'-like, resembling the odour of Skeletocutis stellae (Pilát) Keller and S. subincarnata (Peck) Keller.

Hyphal system monomitic. Subiculum 20-100 $\mu \mathrm{m}$ thick, in places almost lacking, formed by one or two layers. In young parts of the fruit body, fairly thickwalled to thick-walled, sparingly clamped hyphae ((2.5-) $3-3.5(-4) \mu \mathrm{m}$ wide) run parallel to the substrate and form the subiculum. The thickness of 


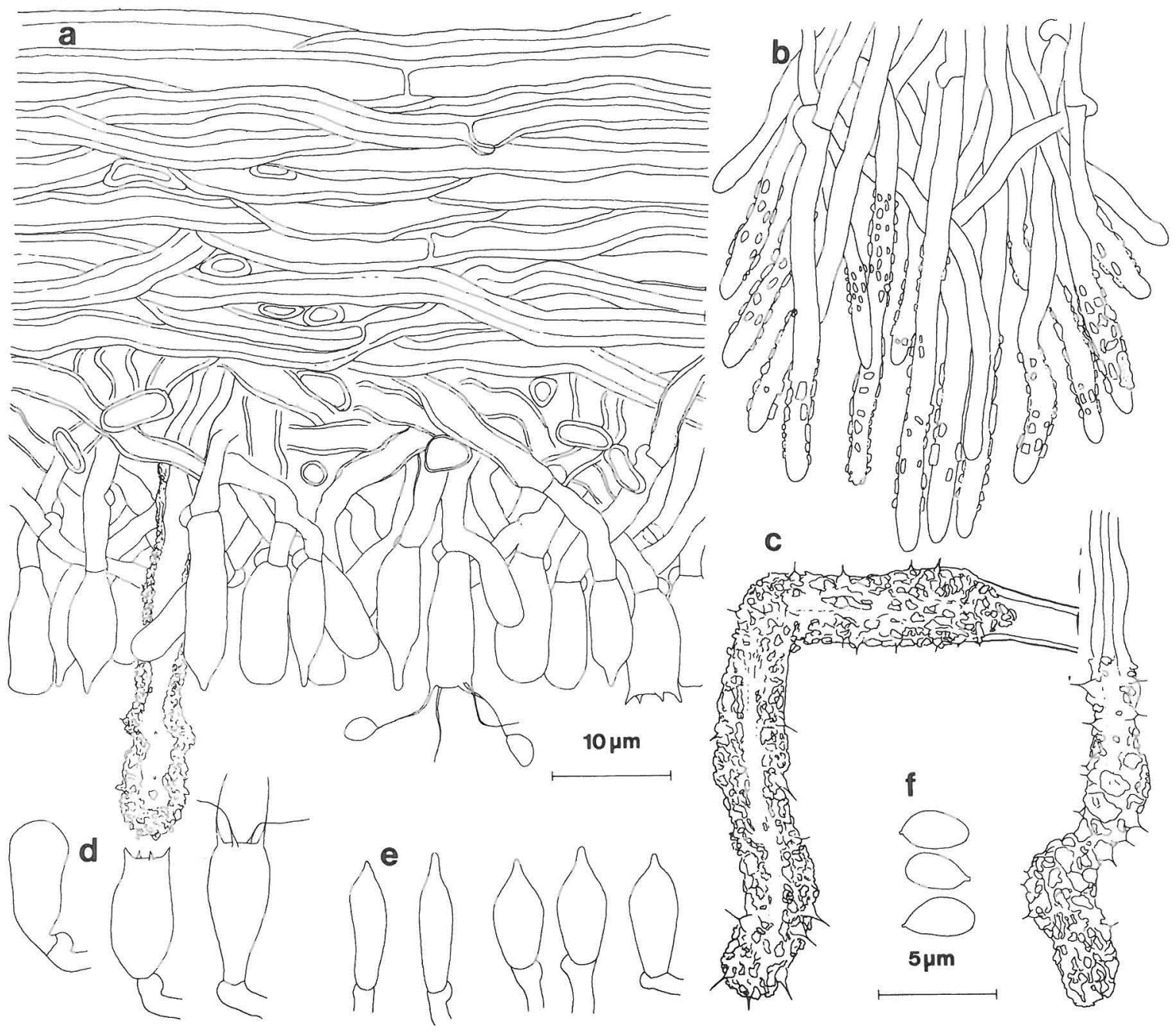

Fig. 1. Skeletocutis jelicii. a) section through hymenium and subiculum, b) encrusted hyphae from a young dissepiment edge, c) heavily encrusted hyphal ends from upper tube, d) basidia, e) cystidioles, f) spores (c-d Kotiranta 3614, others Niemelä).

this layer varies between 20 and $60 \mu \mathrm{m}$, but it can also be totally absent. In older parts parallel subicular hyphae are often lacking or covered with brown resinous matter. This brown line is easily seen under the lens. In old fruit bodies, where the parallel layer is lacking or indiscernible, the subiculum seems to consist of rather thin-walled, $2.5-3.0 \mu \mathrm{m}$ wide, clamped hyphae, which are densely intertwined with thick-walled, $3.0-4.0 \mu \mathrm{m}$ wide, clamped hyphae. Often both subicular layers are present. The thick-walled subicular hyphae develop heavily encrusted ends, which penetrate through the hymenium to the upper parts of the pore openings. These hyphae can easily be taken for the cystidia seen in the genus Junghuhnia Corda emend. Ryvarden, but the rose-thorn shape of some of the crystals, characteristic of the genus Skeletocu$t i s$, can generally be observed without difficult.

Dissepimental hyphae more or less parallel, richly branched, 1.7.-2.0 (-3.0) $\mu \mathrm{m}$ wide, clamped, thinwalled and filled with oily matter. At the pore mouths some hyphae are encrusted. These encrustations are most easily seen in fairly young parts, but may be rare even there. In old parts such hyphae are only seldom seen. The old tubes turn brown because of resinous matter, which also makes the texture difficult to observe.

The hymenium is dense, composed of clavate, (9-) $10-12(-13) \mu \mathrm{m}$ long, 4-5 $\mu \mathrm{m}$ wide basidia with four very thin sterigmata (4-6 $\mu \mathrm{m}$ long), which 'fade' even before the spores are released, and of numerous clavate, $10-13 \mu \mathrm{m}$ long, $3-4 \mu \mathrm{m}$ wide cystidioles with a narrow apical tip. The basidia and cystidioles are basally clamped.

Spores small, broadly ellipsoid, hyaline, thin-walled, smooth, inamyloid, indextrinoid, acyanophilous, $(2.3-) 2.5-3.0 \times(1.3-) 1.6-1.8(-1.9) \mu \mathrm{m}$. 


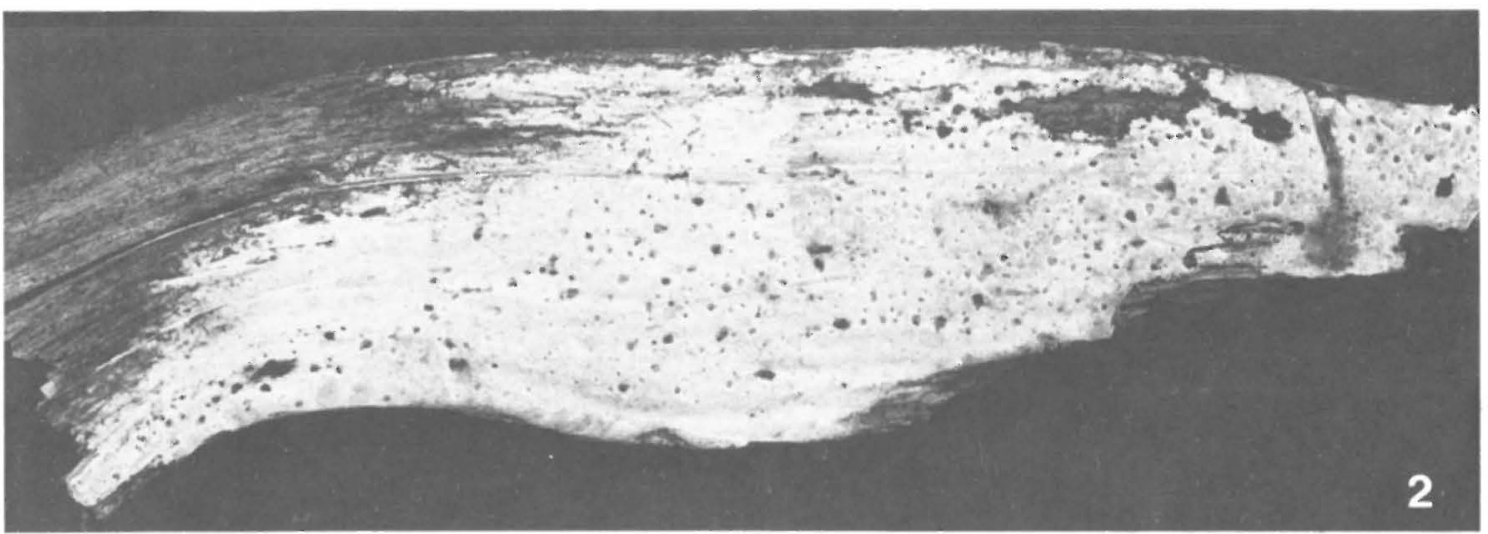

Figs. 2-3. Skeletocutis jelicii, dried specimen. Note the small pores and guttation depressions (Kotiranta 3614). 2: $\times 1 .-3: \times 2.7$

\section{Specimens examined}

Finland. Etelä-Häme. Padasjoki, Vesijako Strict Nature Reserve, Picea abies, soft rotten, decorticated wood in virgin spruce forest, Grid 27ㅌ: 680:39, 26.VIII.1966 Niemelä (herb. Niemelä). - Perä-Pohjanmaa. Tervola, Pisavaara Strict Nature Reserve, Liljalaki SE slope, very strongly decayed, wet Picea abies on the ground, Picea abies dominated virgin forest, Grid $27^{\circ} \mathrm{E}$ : 735:41, 21.IX.1981 Kotiranta 3614 ( $\mathrm{H}$ and herb. Kotiranta). - Inarin Lappi. Inari, Lemmenjoki National Park, Härkäkoski SW, strongly decayed Pinus sylvestris on ground, with Antrodia albobrunnea (Rom.) Ryv. and Phellinus viticola (Schw.: Fr.) Donk, Grid $27^{\circ} \mathrm{E}: 762: 45$, 2.IX.1980 Kotiranta 2417 \& Niemelä (herb. Kotiranta)

\section{Distribution}

For the present only four collections of $S$. jelicii are known. The type locality in Yugoslavia (Tortic \& David 1981) lies at an altitude of almost $1000 \mathrm{~m}$; the other three finds are from Finland. The material is so far too scanty to reveal much about the total distribution area of $S$. jelicii. However, the occurrence at a relatively high altitude in the temperate zone in Yugoslavia gives the impression that the species is at least to some degree dependent on a climate with low temperatures and a snow cover in winter and rather low summer temperatures. It is probable that the climate at the type locality (Abies intermixed with Fagus) is very similar to that in Finland, which is situated in the boreal zone with low winter temperatures, a snow cover half the year or more and relatively warm summers. In fact, the similarities in climatic conditions can be expected to lead to likenesses in the polypore flora, and this kind of distributional pattern (on mountains in Southern and Central Europe, and in lowland forests in the boreal zone) is not unusual among the polypores. Spongiporus fragilis (Fr.) David, for instance, is fairly common throughout Finland in spruce forests, but in Yugoslavia occurs in mountain forests (Tortic 1981) and in Central Europe reaches its maximal occurrences on the mountains (Jahn 1963, Ryvarden 1978). The range of the newly described Antrodiella citrinella Niemelä \& Ryvarden

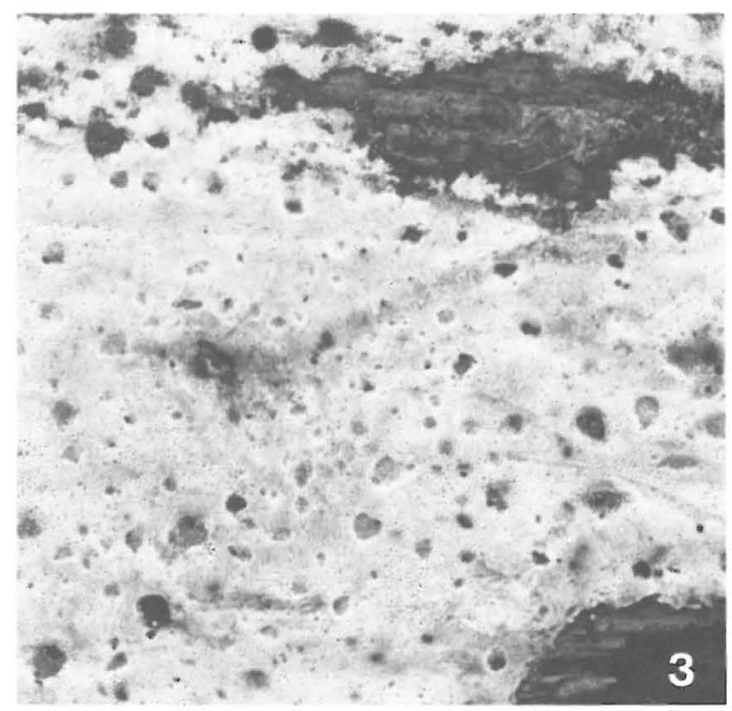

(Niemelä \& Ryvarden 1983) greatly resembles that of S. jelicii.

The three finds from Finland indicate that $S$. jelicii could be a representative of the so-called 'taiga species' (see Eriksson \& Strid 1969), with a northern, and at least slightly continental distribution.

The southernmost Finnish locality, in Etelä-Häme, lies in the Southern boreal zone. The vegatation and polypore flora of this virgin forest (Vesijako Strict Nature Reserve) was described by Kotiranta and Niemelä (1981).

Pisavaara Strict Nature Reserve lies in the Middle boreal zone and its polypore flora is among the best studied in North Europe (Eriksson \& Strid 1969). Niemelä (1980) described the luxuriant slope vegetation of this virgin spruce forest. In Vesijako and Pisavaara the host tree was strongly decayed Picea abies, and no other polypore species were distinguishable on the same trunk. These virgin spruce forests are microclimatically relatively humid, unlike the third area in northernmost Finland. Lemmenjoki National Park lies in the Northern boreal zone, and the vascu- 
lar plant vegetation is poor compared with that of the other two areas. The forests are sparse, dry pine ( $P i$ nus sylvestris) heaths intermixed with Betula pubescens ssp. tortuosa, scattered aspen (Populus tremula) and willows (Salix spp.) on humid brooksides and shores. The field layer of these dry heaths consists predominantly of Calluna vulgaris, Empetrum nigrum ssp. hermaphroditicum, Ledum palustre, Vaccinium myrtillus and $V$. vitis-idaea. Herbs and grasses are few (e.g. Melampyrum pratense, Deschampsia flexuosa, Festuca ovina) and lichens (Cladonia spp). are a dominant feature. The host tree of S. jelicii was strongly decayed Pinus sylvestris, where it grew together with Antrodia albobrunnea and Phellinus viticola. The decay which is observable seems to be of the brown-rot type, but it is possible that it is caused by other woodinhabiting fungi, especially in the collection made in Lemmenjoki, where $A$. albobrunnea was growing on the same trunk.

It is noteworthy that all the collections were made from strongly decayed gymnosperms in protected areas. The Finnish collections were also made in different boreal zones, which gives the impression that $S$. jelicii is not so rare in northern coniferous forests as the scarcity of collections suggests. It can be expected to be found in old virgin forests with much decayed wood anywhere in the boreal zone and on the mountains of Southern and Central Europe. S. jelicii does not seem to be associated with any particular polypore species.

\section{Discussion}

The Finnish resupinate Skeletocutis species most resembling $S$. jelicii are $S$. stellae and $S$. subincarnata. $S$. tschulymica (Pilát) Keller is generally much bigger, grows predominantly on corticated spruces, and has larger pore openings, longer tubes and a sour-sweetish smell. S. stellae and S. subincarnata have the same pungent smell in fresh condition as $S$. jelicii. However, the pores are larger in S. subincarnata, and $S$. stellae is perennial. All the other Finnish Skeletocutis species known so far differ from $S$. jelicii in being dimitic. The thick-walled hyphae in the subiculum (if present) can easily be taken for skeletals but they are sparsely clamped. The encrusted hyphae in the pore mouths seen in S. stellae, S. subincarnata and S. tschulymica are almost lacking in S. jelicii, and the big, encrusted cystidialike hyphal ends in the pore openings are the encrusted structures most easily discerned. At least some crystals can generally be observed to have the characteristic shape resembling a rose thorn. If the shape of those crystals is overlooked, $S$. jelicii resembles the species of the genus Junghuhnia which, however, are clearly dimitic. The shape of the spores is fairly close to that seen in the genus Antrodiella Ryvarden \& Johansen, but in the Finnish material of $S$. jelicii all the spore dimensions are smaller.
The spore size given by Tortic and David (1981) for the Yugoslavian type specimen is slightly longer and wider than in the Finnish specimens. However, the dimitic hyphal system and lack of encrusted hyphae in Antrodiella minimize the risk of confusing the conifer-dwelling species with $S$. jelicii.

In the field $S$. jelicii is recognizable by the whitish colour with brown spots, small guttation depressions, very small pores and the pungent smell. Further, the small subglobose spores are characteristic of $S$. jelicii and separate it from other Finnish Skeletocutis species, which have narrow allantoid spores.

Although $S$. jelicii differs in some respects from the other Finnish members of Skeletocutis (monomitic, subglobose spores, brown-rot (?)) I agree with Tortić and David (1981) that it should be placed in this genus. The small pores, the pungent smell, and above all the sharp-pointed crystals are so characteristic of the members of Skeletocutis, that no other genus seems as suitable for $S$. jelicii.

Acknowledgements. I am especially grateful to Dr. Nils Hallenberg, who first determined one of the Finnish collections. I also thank Dr. Tuomo Niemelä for advice and for pleasant companionship in the Lemmenjoki National Park; he also placed a specimen of $S$. jelicii at my disposal.

The English of this paper was revised by Mrs Anna A. Damström, M.A. The work was supported by a grant from the Emil Aaltonen Foundation.

\section{References}

David, A. 1982: Étude monographique du genre Skeletocutis (Polyporaceae). - Naturaliste Canadien 109: 235-272.

Domański, S. 1963: Dwa nowe rozaje grzybów z grupy "Poria Pers. ex S.F. Gray". - Acta Soc. Bot. Poloniae 32: $731-739$.

Eriksson, J. \& Strid, ^. 1969: Studies in the Aphyllophorales (Basidiomycetes) of Northern Finland. - Ann. Univ. Turku (A II) 40 (Rep. Kevo Subarctic Sta. 4): 112-158.

Jahn, H. 1963: Mitteleuropäische Porlinge (Polyporaceae s. lato) und ihr Vorkommen in Westfalen. - Westfälische Pilzbriefe 4: $1-143$.

Keller, J. 1979: Ultrastructure des hyphes incrustées dans le genre Skeletocutis. - Persoonia 10: 347-355.

Kotiranta, H. \& Niemelä, T. 1981; Composition of the polypore communities of four forest areas in southern Central Finland. - Karstenia 21: 31-48.

Kotlaba, F. \& Pouzar, Z. 1958: Noyé nebo málo známé choroše pro Ceskoslovensko 3. - Ceská Mykologie 12: 95104 :

Niemelä, T. 1980: On Fennoscandian polypores 7. The genus Pycnoporellus. - Karstenia 20: 1-15.

Niemelä, T. \& Ryvarden, L. 1983: Antrodiella citrinella: a new polypore species. - Karstenia 23: 26-30.

Ryvarden, L. 1978: The Polyporaceae of North Europe 2. Inonotus to Tyromyces. - Pp. 219-507. Oslo.

Tortić, M. 1981: Aphyllophorales and some other wood-inhabiting macromycetes from mountain Tara (Serbia, Yugoslavia). - Bull. Mus. Hist. Nat. (Belgrade) B 36: $31-42$.

Tortić, M. \& David, A. 1981: Skeletocutis jelicii nov. sp. (Polyporaceae). - Bull. Soc. Linn. Lyon 50: 217-219.

Accepted for publication on 15 March, 1984 